\title{
Causes of and Preventive Measures for Complacency as Viewed by Officers in Charge of the Engineering Watch
}

\author{
Toni Bielić, Jelena Čulin * (D), Igor Poljak®i) and Josip Orović(i) \\ Maritime Department, University of Zadar, 23000 Zadar, Croatia; tbielic@unizd.hr (T.B.); ipoljak1@unizd.hr (I.P.); \\ jorovic@unizd.hr (J.O.) \\ * Correspondence: jculin@unizd.hr
}

Received: 8 June 2020; Accepted: 13 July 2020; Published: 14 July 2020

check for updates

\begin{abstract}
Complacency has been recognised as a cause of maritime accidents, and there is a need to develop and execute relevant preventive measures. The effectiveness of preventive actions depends on the contribution of the seafarers. Therefore, the purpose of this study was to identify causes and elicit proposals for preventing complacency by officers in charge of the engineering watch. A total of 63 Croatian engineering officers participated in four deliberative workshops, facilitated by an expert in the teaching of leadership and management. As causes of complacency, intensive workload, poor knowledge/understanding of the equipment, steep authority gradient, lack of collaboration, poor communication, efficiency-thoroughness trade-off, crewing strategies, and lack of organisational justice were identified. Efficient training on workload management, adequate familiarisation, reporting issues with technology, producing one's own manuals, more effective leadership courses, more emphasis on non-technical skills as criteria for a promotion, joint workshops on teamwork for land-based managers and seafarers, open and objective performance evaluation, and direct communication between land-based managers and seafarers were proposed as feasible preventive measures. Human-centred design and standardisation of the equipment were evaluated as unlikely to be feasible. Some practical implications from the findings were discussed.
\end{abstract}

Keywords: maritime safety; maritime accidents; human element; complacency; preventive measures; engineering officers

\section{Introduction}

A major part of the aftermath of the accidents or incidents in safety-critical systems is a root cause analysis [1]. Reports on accidents in aviation, medical systems, nuclear power plants, and military and defence operations systems often mention complacency as a contributing factor [2]. Similarly, complacency is recognised as a cause of accidents in the maritime sector. For example, analyses performed as a part of the FP7 SEAHORSE project considered complacency as an underlying accident sub-factor present in $6 \%$ of maritime accidents [3]. According to a study published in 2018, complacent behaviour contributed to $11 \%$ of accidents caused by problems related to technology [4].

However, there is no uniform definition of complacency in the literature [5]. The term complacency has been used in the analysis of accidents and incidents in the aviation community since approximately 1960-1970 [6]. It was included as a coding item for incident reports by the National Aeronautics and Space Administration Aviation Safety Reporting System in 1976 and is defined as "self-satisfaction that may result in no vigilance based on an unjustified assumption of satisfactory system state" [7]. Most research studies deal with technology complacency (referred to as automation-induced complacency, automation-related complacency, automation complacency) and define it in a way that describes the 
relationship between a human operator and an automated system. For example, Wickens et al. [8] refer to complacency "as the state of monitoring before an automation decision aid failure that expresses itself as a delayed or "guessing" response when the decision aid fails to function at all (automation error of omission)". Parasuraman and colleagues [2] identified a core set of features present in various definitions and defined complacency "as poorer detection of system malfunctions under automation control compared with manual control". Bahner et al. [9] investigated complacency effects by comparison of the user's automation verification behaviour with a normative model of "optimal" non-complacent behaviour. Research data indicate that certain individual attitudes contribute to the occurrence of complacency, and therefore accurate assessment of the complacency potential has been proposed as one of the means for preventing complacency-related accidents. Several studies used the automation-induced complacency potential rating scale developed by Singh et al. [10], with items related to trust and perceived reliability of automated systems. Recently, a new scale of automation-induced complacency potential that focuses on attitudes such as using and monitoring has been developed [5].

However, research and analyses of accidents or near misses show that technology complacency is only one of the types of the complacency and that patterns of deteriorating training, maintenance, procedural compliance, and supervision may influence all kinds of safety rules and operating procedures, not just the interaction between humans and technology [1]. Therefore, Hyten and Ludwig [1] provide a broader behavioural definition. They define complacency as a "pattern in which formerly safe behaviours begin varying in form, eventually including deviations that elevate the risk of process incidents and/or put frontline workers at elevated risk of injury. It is a term that describes a particular kind of behavioural trend that can occur within the task-related repertoire of frontline workers as well as within the decision-making repertoire of management". Similarly, as a part of analyses of contributing factors in accidents or near misses in aviation, Fahlgren [6] recognises and defines complacency as "a gradual change in attitudes caused by bad leadership or management". According to Fahlgren, a complacent person "unconsciously does not use available knowledge and resources". Fahlgren mentions four categories of complacency:

- Technology complacency

- $\quad$ Leadership complacency

- Management complacency

- Self-induced complacency

Because similar human and organisational factors affect operational factors in aviation and maritime transport, Fahlgren's concept has been used to analyse complacency as a cause of maritime accidents [11]. Based on our experience as researchers and practitioners (three authors are active or former seafarers (master, chief engineer, and gas engineer), an adaptation of Fahlgren's concept has been chosen for the purpose of this article to address the full extent of the problem that is present in shipping. A brief description of the categories follows.

Technology complacency primarily occurs in multitasking environments when human operators fail to be vigilant in the monitoring of an automated system because they assume that due to highly and consistently reliable systems they may shift alertness to other tasks [12].

Leadership complacency develops due to a leader's poor communication skills and/or undesirable leadership style [13], which often includes self-interest, self-centeredness, and self-love [14]. If crew members feel tense and uneasy, unappreciated, judged harshly, or ignored, they may no longer provide a chief engineer or master with critical information, and the leader is unconsciously not using available knowledge possessed by his crew. The same thing may happen when leaders have a great reputation, and crew members are afraid to challenge their decisions.

Similarly, management complacency occurs if crew members feel forced to disregard procedures to comply with the company's requests or feel ignored and not listened to by the shipping company. 
Due to a bad relationship with the management, gradually their creativity and motivation will be reduced and they will stop using their knowledge [15].

On some occasions, a change in behaviour occurs due to frustration caused by waiting for promotion longer than expected and a feeling of being non-appreciated. Unconsciously, persons with certain personality traits may adapt dangerous behaviour and this self-induced complacency may jeopardize maritime safety [16].

Currently, studies on maritime safety mostly explore causes of the accidents and interventions by various stakeholders (International Maritime Organization (IMO), governments, ship-owning companies, classification societies) and show that to make maritime transport safer, they must be based on a conceptualization of the whole system including numerous stakeholders (manufacturers, vessel owners, manning companies, regulatory bodies, crew) [17-20]. However, a smaller number of studies position seafarers as actors whose own perspectives should contribute to the formulation of instruments for safety improvement [21]. Namely, peculiarities of the shipboard environment may significantly hamper the effectiveness of preventive measures formulated without the significant contribution of the seafarers. Moreover, compliance with measures developed in such a way may contribute to the stress and fatigue and defeat the purpose for which they were introduced [22].

To ensure safe navigation, it is necessary that personnel in the ship's machinery space competently carry out their duties. Therefore, measures which aim to reduce the risk of complacency are important for achieving safe engineering operation. Many interrelated and complex factors determine the level of effectiveness of maritime safety policy instruments related to complacency and they can vary significantly depending on an area of interest. Hence, it is necessary to involve officers in charge of the engineering watch (engineering officers) in the development of such measures to improve the quality and breadth of information on which decisions are made. To formulate measures aimed at preventing complacency properly, one of the necessary steps is to examine the attitudes and opinions of seafarers related to their feasibility, particularly because interventions are mostly targeted toward them. This study was designed to address this research need.

\section{Methodology}

In the period from February 2018 to December 2019, four deliberative workshops were organized at the University of Zadar, Croatia.

The deliberative workshop, a form of facilitated group discussion well-established in the social sciences, was chosen because it, unlike in-depth interviews and large-scale attitudinal surveys, allows participants to reflect on their position and encounter with the views of others, thus enabling identification of an informed, considered, and collective view [23]. Moreover, a wider range of attitudes, views, and opinions surrounding issues than is typically admitted by expert assessments may be elicited [24]. Briefly, at the beginning of the workshop, the researcher provides information about the subject, followed by a group discussion by participants. The advantage of this approach is that it allows participants to be better acquainted with the problem by intentional and direct input of new information by the facilitator. Opportunity to consider an issue in-depth is ensured to avoid poorly-informed solutions [25]. According to Fishkin [26], deliberation produces "a representation of what the public would think under good conditions for thinking about it". This feature was crucial for the choice of this approach because, considering the broad range of definitions of complacency (sometimes somewhat vague) occurring in the literature, accidents' reports, general letters from companies, media and so on, it was important to clarify the term and explain which issues the participants are expected to address. An additional advantage of the deliberative workshop, the fact that participants' views may be developed and transformed, due to insight into the different perspectives and attitudes expressed during a discussion [23], was important for its choice because experiences in the maritime sector differ considerably.

The half-day workshops were facilitated by one of the authors, a workshop leader for maritime crew resource management. There were several stages. Each workshop began with a short presentation 
on complacency as a contributing factor in accidents. Various definitions of the complacency from scientific literature and accident reports were presented. Fahlgren's definition and classification of complacency, with examples of accidents from the aviation and maritime sectors for each of four categories, were given. The participants were asked to present examples from their on board experience that illustrate different categories. The facilitator explained that examples might also be situations that resulted in no incident or accident, but complacent behaviour or behaviour that may lead to complacency occurred. A group discussion followed. The facilitator encouraged each participant to provide an example. These examples then were discussed concerning the potential cause, and the facilitator ensured that every participant had an opportunity to speak. Participants were asked to write down the most illustrative examples from their experience. Then they were presented with posters on which four categories of complacency were shown in the table. Participants were invited to write down causes for each category. Once causes had been identified, corresponding preventive measures proposed in the literature were presented. Participants were asked to evaluate those measures and to propose additional ones. The facilitator encouraged participants to put emphasis on the feasibility of proposed measures and to label measures as feasible or unlikely to be feasible.

A total of 63 engineering officers (all men) participated in the research: 23 in the 1st, 17 in the 2nd, 8 in the 3rd, and 15 in the 4th workshop. The positions on board represented in the sample were second engineer (34), third engineer (24), and fourth engineer (5). All participants were active seafarers, enrolled in a special education programme for seafarers in marine engineering, offered by the Maritime Department of the University of Zadar. The programme enables engineering officers to meet requirements for the award of vocational competency certificates for chief engineer. The requirement for enrolment in programme is to have at least a minimum of 36 months of aggregated sea service as an engineer officer in charge of a watch in an engine room with a machine propulsion power of $750 \mathrm{~kW}$ or more. To elicit a diverse range of viewpoints, participants who work on various types of vessels managed by domestic and foreign companies were selected. The average sea service of participants was nine years and varied from four to twenty years. This approach was designed to select marine engineers with relevant information and experience, but who are not yet team leaders and probably do not have an opportunity to express their opinions often.

Materials for analysis were notes and four tables produced during workshops. Their content was analysed by assigning codes to yield thematic categories, and the final list of preventive measures corresponding to identify causes of complacency was formed by summarizing results obtained in all workshops. Response frequencies were assigned to obtain the feasibility of preventive measures.

\section{Ethical Considerations}

The purpose of the research was explained at the beginning of the workshop. The participants were informed that their participation was voluntary, that they may choose not to participate or stop at any point in time, and that their answers would be treated anonymously. Verbal consent was obtained to avoid the fear of the participants that anonymity may be jeopardised by written consent. Data were stored with the authors and treated with strict confidentiality.

\section{Results and Discussion}

Group discussions done after the introduction by the facilitator revealed that participants had various opinions about the meaning of the term complacency and that most of them considered complacency as a sort of laziness, sloppiness, or incompetence. Therefore, we believe that our assumption that survey or interviews, which are performed preferably without or minimal influence by the researcher to elicit participants' existing views or to understand what the public think about the familiar subject [23], would not be a proper method for our research, was correct. Clarifying the fact that a complacent person behaves in a certain way unconsciously, and that consequently, failures are not intentional, was important for providing examples and identifying causes, because a gradual change in attitudes may happen due to numerous reasons at any level of the system and to everybody. 
Also, importantly, understanding that complacency is not related to violations (intentional failures based, for example, on feeling being forced, or not caring for consequences) enabled participants not to look for preventive measures aimed at "disciplining" operators. Table 1 shows the identified causes and preventive measures evaluated as feasible or not likely to be feasible by participants.

Table 1. Causes and preventive measures for complacency identified and proposed by study participants.

\begin{tabular}{|c|c|c|}
\hline Complacency Category & Cause & Preventive Measure \\
\hline Technology & $\begin{array}{c}\text { Poor knowledge/understanding of } \\
\text { equipment }\end{array}$ & $\begin{array}{c}\text { Efficient training on workload management } \\
\text { Human-centred design * } \\
\text { Standardisation of the equipment * } \\
\text { Adequate familiarisation } \\
\text { Safety reporting } \\
\text { Producing one's own manuals }\end{array}$ \\
\hline Leadership & $\begin{array}{l}\text { Steep authority gradient } \\
\text { Lack of collaboration } \\
\text { Poor communication }\end{array}$ & $\begin{array}{l}\text { Effective leadership and teamwork training } \\
\text { More emphasis on non-technical skills as criteria for promotion }\end{array}$ \\
\hline Management & $\begin{array}{l}\text { Efficiency-thoroughness } \\
\text { Trade-offCrewing strategies }\end{array}$ & Joint workshops on teamwork for land-based managers and seafarers \\
\hline Self-induced & Lack of organisational justice & $\begin{array}{l}\text { Evaluating performance objectively and providing feedback } \\
\text { Direct communication between land-based managers and seafarers }\end{array}$ \\
\hline
\end{tabular}

\subsection{Technology Complacency}

As mentioned before, technology complacency is the most frequently addressed among other categories, in the practice, and the literature. Therefore, it was expected that most examples included overreliance or over compliance with the automated systems. The most illustrative examples follow:

3E: "I was on deck and watching loading fuel from a barge. The chief engineer was in the engine room and monitored quantities loaded and telling quantities and flow rate to the second engineer. Near the end of the loading, the chief informed the second to reduce the loading rate. Shortly afterward, the tank overflowed. The chief was surprised because the monitor showed that the tank was not filled yet. No one checked manually."

2E: "We were at a liquid cargo terminal. The manifold was checked and after permission from the terminal unloading cargo began. The flow rate of the pumps is set in the cargo room. He set limits and alarms and went to control the installation of the auxiliary pump in one tank on deck. He forgot the walkie-talkie in the cargo room. During his stay on deck, there was a request to reduce the discharge rate from the terminal, but the cargo officer, without a walkie-talkie, did not respond. There was an overload of the unloading line and the automatic shutdown did not turn on and there was a spill on deck. The cargo officer later said he had too much to do at the same time."

After discussions about the examples presented, in summary, intensive workload, poor knowledge, and understanding of equipment, were identified by participants as causes of technology complacency in Table 1.

A high workload, as one of the work-related stressors (others are long working hours, low control, and work-role conflict), has been identified as one of the most important stressors in seafaring recently [27]. Namely, technical developments and increased automation made many manual tasks redundant and enabled the reduction in a shipboard crew, as required by economic conditions and striving for profitability [28]. Concurrently, new tasks have emerged, particularly associated with environmental protection [22]. Also, the paperwork demands, imposed by industry stakeholders to improve safety standards and clarify chains of responsibility, have increased to the extent of being considered a safety risk itself [29]. Intensive and prolonged working hours negatively influence health, both physiologically and psychologically, and consequently the safety of seafarers, depending on the size and type of ships, as well as the position and function on board [30]. Excessive workload contributes to fatigue, and a fatigued operator may choose strategies that require less effort to execute, 
neglecting aspects of risk [29]. In many studies, the engine crew reported high stress levels, in some cases significantly higher than the deck department. Also, research suggests that officers are affected by downsizing, technological, and organizational changes more than non-licenced seamen [28].

Preventing measures relating to the health of workers may be classified as tertiary (dealing with stress outcomes), secondary (help in coping with stressors), and primary (reducing the main occupational stressors and risks) [27]. However, some studies show that the efficacy of such interventions is low [31]. Reduction of long working hours, increased number of crew, and unbroken periods of rest and sleep have been proposed as the main primary interventions in seafaring [27]. Nevertheless, our participants dismissed those measures as not feasible. Namely, they thought that during their careers changes in the industry resulted in escalated instead of mitigated occupational stressors and that they could not see how this trend might be changed. This opinion is supported by research, which shows that more favourable working conditions are unlikely to be attained, due to the current situation in the maritime industry, which enables ship owners to replace seafarers from higher-income countries and countries with social security support with seafarers from lower-cost crewing countries [32]. On the other hand, the participants propose more efficient training on workload management that can be performed on board, during periods with a reduced workload, which should include shifting roles between seafarers to be better acquainted with other jobs, thus enabling prioritizing and collaboration.

Inadequate equipment design and the existence of numerous user interfaces that differ significantly have been recognised as a contributing factor to maritime accidents and as preventive measures, standardisation and human-centred design have been proposed [3]. To improve safe and effective navigation, IMO published guidelines for the standardization of a user interface design for navigation equipment (standardized mode), guidelines for the presentation of navigational-related symbols, terms, and abbreviations (SN.1/Circ.243.Rev1), and performance standards for the presentation of navigation-related information on shipborne navigational displays (MSC.191(79)) [25]. The design of instruments and equipment in the engine room may also differ significantly and increase the burden associated with becoming familiar with instruments and equipment. Additionally, poor design and inadequate manuals contribute to the workload, fatigue, and stress. Therefore, it was expected that participants of this study mentioned human-centred design as a preventive measure. However, most of the participants evaluated this measure as unlikely to be feasible with an explanation that the purchase of the equipment is decided based on factors (primarily price) other than usability and that producers do not care about users' opinions. Unfortunately, these opinions reflect the research showing that the design process is constrained by insufficient collaboration between designers and operators [33]. Current practice, which should enable the involvement of the operators and improvements of design, includes sending a "change request" to the company. The company evaluates it and approved requests are forwarded to the classification society for approval. Approved changes are incorporated into ship design manuals and drawings with approved class notification, and may be added to rules for classification of ships. However, participants felt that it was worthless because they thought their suggestions are rarely accepted. Similar reasons, mostly related to the interests of the producers and bases to make purchase decisions, were provided for the evaluation of the standardisation as unlikely to be feasible. As something that may be done, participants stated putting more emphasis on possible failures and limitations of instruments during familiarisation. Reporting issues and concerns with technology to the chief engineer and forwarding comments to the technical sector of the company have also been recommended because reporting works well for some companies of the participants. That could also contribute to producing one's own instructions and maintenance manuals, as a part of the ship management system. These documents should be produced by the technical sector in collaboration with users. Such documents should be digest versions, adapted to be more appropriate regarding language and complexity in comparison with original manuals, which are often extensive or written without full insight into user requirements. 


\subsection{Leadership Complacency}

Almost all participants mentioned that at some point in their career they were witnesses of the poor leadership that negatively influenced safety on board. A strong hierarchical structure is still present in the multinational and multicultural environment of shipping [31], and a steep gradient authority, sometimes accompanied by inappropriate behaviours, was identified during all workshops (Table 1), as illustrated by one example:

3E: "We were leaving the port, the engine was working "dead slow ahead" when "stop engine" arrived from the bridge. Shortly after that, there was a blackout. At that moment, the chief engineer started issuing orders to the present officers, which did not affect finding the cause of the malfunction. They did not say anything and did not take any initiative. Later I learned that some of them assumed what happened and how to fix it, but they were afraid to tell because he used to yell and mock them."

According to research and theory, team dynamics is greatly influenced by leadership [34]. Because clearly defined hierarchy and role distribution are present in the maritime sector, leadership and management are even more important than in similar safety-critical systems [35]. A study published in 2017 [35] revealed that all crew resource management programmes in the maritime sector contain modules related to leadership and management (authority, assertiveness, leadership/following, obedience, maintaining standards, planning, briefings, coordination), with an average coverage of $35 \%$ within a program, while the share of the module co-operation (communication, teamwork, collaboration, feedback, influencing, conflict resolution, exchange of objections, challenge, and response) is $23 \%$. On the other hand, in air traffic control, the nuclear power industry, and the oil and gas industry, module co-operation prevails. For example, in the nuclear power industry, the share of leadership and management is $16 \%$ and co-operation $23 \%$. Considering the role of the leader on board ship it is obvious that leadership style is extremely important. However, due to the diversity of situations that may occur on board ships, there is no "one size fits all" leadership style and there is a need to switch between styles to complete a task safely [36]. Nevertheless, regardless of the style applied, leader's traits may strongly influence the atmosphere and performance. Unfortunately, not all leaders possess desirable leadership qualities as identified by Berg [13]: "clear two-way communication, "tough empathy", openness to criticism, empathy towards different cultures, ability to create motivation and sense of community, knowing the crew's limitations, being a team player", and experience and analyses of accidents show that inappropriate leadership played a role in numerous maritime accidents.

A lack of collaboration, as a result of groupthink, and a lack of challenge and response as a reaction to charismatic leadership have also been identified by some participants. One example illustrates this:

2E: "My company decided to send us to an ERM (engine-room resource management) course.

The course makes sense in theory, but as it turned out, nothing changed on my last ship. Everyone is just doing his job quietly. Chief never demands solutions from us. He tells us what and how to do, but he is a great guy who knows the job."

Effective communication is essential when it comes to maritime safety. However, it is often a critical issue, particularly for multicultural and multilingual crews, and communication problems (lack of communication, one-sided or restricted communication, misinterpretation of information) have been identified as a contributing factor to the majority of accidents [37]. As preventive measures for leadership complacency, effective leadership and teamwork training, and putting more emphasis on non-technical skills as criteria for selection and promotion have been proposed. Mandatory training in leadership, resource management, and team-working skills at the operational level and leadership and management skills at the management level have been required by the International Convention on Standards of Training, Certification and Watchkeeping for Seafarers (STCW Convention) since 2010 and delivered by various maritime education and training institutions worldwide. However, studies on the effectiveness of the training found that it varies considerably, and some studies offer limited 
evidence [35]. For example, an analysis of the relevant perspectives of seafarers across different regions revealed that there is a need to improve teamwork and leadership training [36]. According to the opinions of our participants, cultural influences should be not only addressed as a topic of lectures but also considered during planning and deliverance of the training, to ensure understanding and openness of the trainees. Furthermore, including more recent examples of accidents and encouraging trainees to share their own experiences are important to cultivate relevant skills. Putting more emphasis on non-technical skills as criteria for promotion was also proposed as a way to select leaders who will be able to obtain the most from the crew.

\subsection{Management Complacency}

Experiences related to management complacency were also mentioned during all workshops. One example:

3E: "The company rewards us bonuses in a way that bonuses are earned if the cost of the ship stays within budget. The technical sector does not order original parts. For example, a set of auxiliary engine valves they buy costs $\$ 6,000$ while the original one costs $\$ 18,000$. Such a replacement set does not last long and valve failures are far more common than for the original version. We sent complaints from the ship; we did not receive any explanation. I think we will stop caring."

The efficiency-thoroughness trade-off and prevailing crewing strategies in Table 1 were recognised by participants as causes of the management complacency following research. Namely, the requirements for profitability in the shipping industry affect the day to day routines because they resulted in reduced manning, more diverse crews (with a growing share of crews from low- and middle-income countries), labour intensification, increased automation, and faster turnaround schedules [38]. Economic considerations have to be balanced with the time and measures taken. As a result, "The dilemma facing sharp end operators is that they are supposed to be efficient rather than thorough, except in cases where the outcome shows that they should have been thorough rather than efficient" [18]. Contradictory requirements raised by the owners, port operators, and authorities seem to create conflicts particularly for midlevel managers [28]. The presence of contradictory requirements may result in more conflicts with companies if the seafarer is primarily oriented towards professional norms.

However, due to the free market structure of the maritime sector, barriers to request more favourable working conditions exist [32]. Namely, there is a risk of cheaper labour supplies willing to work for the conditions offered. Additionally, current crewing strategies (outsourcing of crewing management and the extended use of contract employment, unsynchronized rotation of officers and crew between different vessels) also may contribute to poor communication, inexecutable procedures, lack of loyalty to a company, dysfunctional interaction, and fear of retaliation [39] and thus lead to the development of complacency as can be seen from the following example:

2E: "We have to deal with extensive documentation related to the condition of individual devices. Administration takes a lot of time. We gave the company suggestions for unifying some data in terms of ways and places for record management to give us more time for concrete work. They never answered us, but we heard that we could leave if we want. We don't ask anything anymore and we do as we are told."

Preventative measures such as more permanent employment and higher retention rates, which are eventually related to profitability, were dismissed due to the current situation in shipping. Joint workshops on teamwork for land-based managers and seafarers were proposed as an only feasible measure, to enable wider perspectives and to improve two-way communication (sometimes shipowners are not aware that certain efficiency efforts jeopardise safety). 


\subsection{Self-Induced Complacency}

Examples that included self-induced complacency were not given by participants. This fact was somewhat expected, considering its origins and relation to some undesirable individual characteristics such as immaturity or impatience. Nevertheless, some examples of situations that were related to self-induced complacency were provided:

4E: "My colleague was second for the same company for five years and had all positive reports. He was promised promotion. However, another person, who had been with the company for only two years, was promoted. He told me that on the next ship that guy was chief, while he remained the second. He noticed that guy did not know some things. He said he didn't want to interfere in his business even though he knew what he was doing wrong."

3E: "I and the third officer, who was second on the previous ship, serviced the auxiliary engine. He found that the replacement cylinder head gasket did not fit completely and needed to be adapted manually. I suggested that was not a good idea because it would probably get loose quickly. After my warning, he agreed and told the manager to procure the original seal. It was normal for him not to think anymore."

Examples given by the facilitator were analysed, and factors that promote self-induced complacency identified by participants included unfair treatment, unjustified reward distribution, the fairness of the resource allocation, and inadequate communication related to performance. They can be summarised as a lack of organisational justice in Table 1. Organisational justice, perception of just or unfair treatment on the job, strongly influences employee's attitudes and behaviours such as job satisfaction, organisational citizenship behaviour, and counter-production behaviours [40], and it is also related to stress and burnout [41]. Three dimensions of the organisational justice, distributive, procedural, and interactional justice, involve individual valuations of ethics, managerial behaviour, and morality [42]. Organisational justice refers to the perceived fairness of how rewards and costs are shared, and procedural justice refers to the perception of fairness regarding the process in which the gains are distributed. Interactional justice comprises informational justice (the adequacy of explanations given and inter-personal justice (the quality of interpersonal treatment received during the enactment of a decision-making procedure) [43]. In the maritime sector, an uneven distribution of income, privileges, and working conditions based on strict hierarchy, discrimination according to nationality expressed as disadvantaged employment contracts, and an unequal distribution of workload may contribute to perceptions of organisational justice [40]. A study published in 2014 [40] revealed that perceptions of organisational injustice influenced employees' propensity to morally disengage, and moral disengagement was positively related to self-reported deviant work behaviours related to safety compliance, safety participation, and risk-taking. Interventions to increase the salience of moral involvement, ethical awareness, individual responsibility, establishing fair working conditions, establishing explicit criteria for why certain employees are treated differently, encouraging a climate of honesty and openness, involvement of employees in the decision-making process, and training supervisors in organisational justice principles were proposed [40]. Participants of this study recommended the following as feasible preventive measures: more objective performance evaluation and providing feedback by human resource managers. Additionally, direct communication between land-based managers and seafarers (for example, round tables or meetings) has a potential to improve the feeling of being important and listened to.

\subsection{Limitations of the Study and Suggestions for Further Research}

It is important to note the limitations of our study. One limitation is that our sample consisted of Croatian citizens only, and it is important to caution against extrapolating across the maritime community. The effects of national culture on various aspects of safety can be important [13], and individuals belonging to different nationalities may respond differently. Thus, one suggestion for 
future research would be to include participants of various nationalities. Additionally, our participants enrolled in the programme that enables them to be promoted. Therefore, seafarers that take great interest in their work and are more motivated are possibly over-represented in the sample. Similarly, younger officers are over-represented, and older officers may be more affected by rapid technological and organisational changes [44]. Thus, future research could focus on collecting experiences and proposals from the whole target population. Moreover, although confidentiality was assured to participants, social desirability bias may also have positively influenced the results. Participants may have been cautious of endangering their jobs by openly reporting their work experiences [32].

\section{Conclusions}

In seeking to optimise the safety of shipping there is a need to understand sources of human error and develop instruments that address underlying contributory factors. To reduce the risk of accidents and incidents, the originating conditions under which complacent behaviour occurs should be identified. It is important to involve seafarers in the process to ensure getting the whole picture and to improve the effectiveness of the prevention measures.

To the best of our knowledge, this is the first study addressing the views of the officers in charge of the engineering watch regarding complacency. The findings from the present study indicate that engineering officers think that working conditions in contemporary shipping, unfortunately, enable the occurrence of complacency. As contributory factors, they identify intensive workload, poor knowledge/understanding of the equipment, steep authority gradient, lack of collaboration, poor communication, efficiency-thoroughness trade-off, crewing strategies, and lack of organisational justice.

The particularity of living and working conditions on board ships amplifies the need to involve all stakeholders in the development of safety risk mitigation instruments. Results of the study offer insights into the opinions of the engineering officers on feasible preventive measures. They identified stakeholders with the potential to intervene and improve conditions by various actions, mostly related to fostering co-operation. It seems that there is a need to put additional efforts in training and assessing non-technical skills because both ship owners and seafarers may benefit from a more positive work environment.

Considering the importance of the effectiveness of instruments for improving maritime safety, this study can be seen as laying the groundwork for future research. Besides the proposals mentioned in a previous section, future research should also reveal why preventive measures that were evaluated by participants as feasible are mostly expected to be executed by shipping companies, and measures dismissed as not to be feasible should be formulated by other stakeholders.

Author Contributions: Conceptualization, T.B., and J.Č.; Methodology, T.B., J.Č., I.P. and J.O., Validation, T.B., J.Č., I.P. and J.O.; Formal analysis, T.B., J.Č., I.P. and J.O.; Investigation, T.B.; Resources, T.B.; Data curation, T.B.; Writing-original draft preparation, J.Č.; Writing-review and editing, T.B., I.P. and J.O. All authors have read and agreed to the published version of the manuscript.

Funding: This research received no external funding.

Acknowledgments: The authors wish to thank all engineering officers who participated in this study. Many thanks are also owed to Tina Brković for administrative support.

Conflicts of Interest: The authors declare no conflict of interest.

\section{References}

1. Hyten, C.; Ludwig, T.D. Complacency in process safety: a behavior analysis toward prevention strategies. J. Organ. Behav. Manag. 2017, 37, 240-260. [CrossRef]

2. Parasuraman, R.; Manzey, D. Complacency and bias in human use of automation: an attentional integration. Hum. Factors 2010, 52, 381-410. [CrossRef] [PubMed] 
3. Turan, O.; Kurt, R.E.; Arslan, V.; Silvagni, S.; Ducci, M.; Liston, P.; Schraagen, J.M.; Fang, I.; Papadakis, G. Can we learn from aviation: safety enhancements in transport by achieving human orientated resilient shipping environment. Transp. Res. Procedia 2016, 14, 1669-1678. [CrossRef]

4. Bielić, T.; Hasanspahić, N.; Čulin, J. Preventing marine accidents caused by technology-induced human error. Pomorstvo 2017, 31, 33-37. [CrossRef]

5. Merritt, S.M.; Ako-Brew, A.; Bryant, W.J.; Staley, A.; McKenna, M.; Leone, A.; Shirase, L. Automation-induced complacency potential: Development and validation of a new scale. Front. Psychol. 2019, 10, 225. [CrossRef] [PubMed]

6. Fahlgren, G. Life Resource Management CRM E Human Factors; Creative Book Publishers: Ridgefield, WA, USA, 2005; ISBN 978-0-9754818-8-2.

7. Billings, C.; Lauber, J.; Funkhouser, H.; Lyman, E.; Huff, E. NASA Aviation Safety Reporting System; U.S. Government Printing Office: Washington, DC, USA, 1976.

8. Wickens, C.D.; Clegg, B.A.; Vieane, A.Z.; Sebok, A.L. Complacency and automation bias in the use of imperfect automation. Hum. Factors 2015, 57, 728-739. [CrossRef] [PubMed]

9. Bahner, J.E.; Hüper, A.-D.; Manzey, D. Misuse of automated decision aids: Complacency, automation bias and the impact of training experience. Int. J. Hum. Comput. Stud. 2008, 66, 688-699. [CrossRef]

10. Singh, I.L.; Molloy, R.; Parasuraman, R. Automation-induced "complacency": Development of the Complacency-Potential Rating Scale. Int. J. Aviat. Psychol. 1993, 3, 111-122. [CrossRef]

11. Bielić, T.; Vidan, P.; Mohović, R. Complacency-mayor cause of maritime casualties. Pomorstvo 2010, 24, 247-260.

12. Mahlfeld, W.; Hasse, C.; Grasshoff, D.; Bruder, C. The effect of complacency potential on human operators' monitoring behaviour in aviation. In Human Centred Automation; De Waard, D., Gérad, N., Onnasch, L., Manzey, D., Eds.; Shaker Publishing: Maastricht, The Netherlands, 2011; pp. 133-144. ISBN 978-90-423-0406-2.

13. Berg, H.P. Human factors and safety culture in maritime safety (revised). TransnavInt. J. Mar. Navig. Saf. Od Sea Transp. 2013, 107, 107-115. [CrossRef]

14. Low, K.C.P. How to Eliminate or Reduce Egos and Be a Better Leader; Social Science Research Network: Rochester, NY, USA, 2015.

15. Bielić, T.; Predovan, D.; Čulin, J. the role of the master in improving safety culture onboard ships. TransnavInt. J. Mar. Navig. Saf. Sea Transp. 2017, 11, 121-124. [CrossRef]

16. Fahlgren, G. Human Factors; AuthorHouse: Bloomington, IN, USA, 2011; ISBN 978-1-4678-7292-8.

17. Aylward, K.; Weber, R.; Man, Y.; Lundh, M.; MacKinnon, S.N. “Are you planning to follow your route?" The effect of route exchange on decision making, trust, and safety. J. Mar. Sci. Eng. 2020, 8, 280. [CrossRef]

18. Schroder-Hinrichs, J.-U.; Hollnagel, E.; Baldauf, M. From Titanic to Costa Concordia-a century of lessons not learned. Wmu J. Marit. Aff. 2012, 11, 151-167. [CrossRef]

19. Maglić, L.; Valčić, S.; Gundić, A.; Maglić, L. Voice communication systems impact on navigating officers. J. Mar. Sci. Eng. 2020, 8, 197. [CrossRef]

20. Hetherington, C.; Flin, R.; Mearns, K. Safety in shipping: The human element. J. Saf. Res. 2006, 37, 401-411. [CrossRef]

21. Valdez Banda, O.A.; Goerlandt, F. A STAMP-based approach for designing maritime safety management systems. Saf. Sci. 2018, 109, 109-129. [CrossRef]

22. Akamangwa, N. Working for the environment and against safety: How compliance affects health and safety on board ships. Saf. Sci. 2016, 87, 131-143. [CrossRef]

23. Burchardt, T. Deliberative research as a tool to make value judgements: Qual. Res. 2013. [CrossRef]

24. Groves, C.; Meenakshisundaram, S.; Thomas, P.J. Second-generation biofuels: Exploring imaginaries via deliberative workshops with farmers. J. Responsible Innov. 2018, 5, 149-169. [CrossRef]

25. Corner, A.; Parkhill, K.; Pidgeon, N.; Vaughan, N.E. Messing with nature? Exploring public perceptions of geoengineering in the UK. Glob. Environ. Chang. 2013, 23, 938-947. [CrossRef]

26. Kahane, D.J. (Ed.) Deliberative Democracy in Practice; UBC Press: Vancouver, BC, Canada, 2010; ISBN 978-0-7748-1677-9.

27. Slišković, A.; Penezić, Z. Occupational stressors, risks and health in the seafaring population. Rev. Psychol. 2015, 22, 29-40. [CrossRef]

28. Rydstedt, L.W.; Lundh, M. An ocean of stress? The relationship between psychosocial workload and mental strain among engine officers in the Swedish merchant fleet. Int. Marit. Health 2010, 62, 168-175. [PubMed] 
29. Österman, C.; Hult, C. Administrative burdens and over-exertion in Swedish short sea shipping. Marit. Policy Manag. 2016, 43, 569-579. [CrossRef]

30. Oldenburg, M.; Jensen, H.-J. Stress and strain among seafarers related to the occupational groups. Int. J. Environ. Res. Public Health 2019, 16. [CrossRef]

31. Oldenburg, M.; Jensen, H.-J.; Wegner, R. Burnout syndrome in seafarers in the merchant marine service. Int. Arch. Occup. Environ. Health 2013, 86, 407-416. [CrossRef]

32. McVeigh, J.; MacLachlan, M. A silver wave? Filipino shipmates' experience of merchant seafaring. Mar. Policy 2019, 99, 283-297. [CrossRef]

33. Shorrock, S.T.; Williams, C.A. Human factors and ergonomics methods in practice: Three fundamental constraints. Theor. Issues Ergon. Sci. 2016, 17, 468-482. [CrossRef]

34. Marlow, S.L.; Lacerenza, C.N.; Paoletti, J.; Burke, C.S.; Salas, E. Does team communication represent a one-size-fits-all approach? A meta-analysis of team communication and performance. Organ. Behav. Hum. Decis. Process. 2018, 144, 145-170. [CrossRef]

35. Havinga, J.; De Boer, R.J.; Rae, A.; Dekker, S.W.A. How did crew resource management take-off outside of the cockpit? A systematic review of how crew resource management training is conceptualised and evaluated for non-pilots. Safety 2017, 3, 26. [CrossRef]

36. Sanjeev Vakil, K. Approaches to Teamwork and Leadership Training in Maritime Education and Training Institutions: A Comparative Analysis of the Perspectives of Seafarers towards Teamwork and Leadership across Different Regions. Master's Thesis, World Maritime University, Malmö, Sweden, 2019.

37. Lützhöft, M.; Grech, M.R.; Porathe, T. Information environment, fatigue, and culture in the maritime domain. Rev. Hum. Factors Ergon. 2011, 7, 280-322. [CrossRef]

38. McVeigh, J.; MacLachlan, M.; Coyle, C.; Kavanagh, B. Perceptions of well-being, re silience and stress amongst a sample of merchant seafarers and superintendents. Marit. Stud. 2019, 18, 139-158. [CrossRef]

39. Oltedal, H.A.; Engen, O.A. Local management and its impact on safety culture and safety. Saf. Reliab. Risk Anal. Theory Methods Appl. 2009, 2, 1423-1430.

40. Hystad, S.W.; Mearns, K.J.; Eid, J. Moral disengagement as a mechanism between perceptions of organisational injustice and deviant work behaviours. Saf. Sci. 2014, 68, 138-145. [CrossRef]

41. Sökmen, A.; Ekmekçioğlu, E. The relationship between organizational justice, organizational commitment and intention to leave: Investigating gender difference. Int. J. Bus. Manag. 2016, 5, 27-31.

42. Top, M.; Tekingunduz, S. The Effect of Organizational Justice and Trust on Job Stress in Hospital Organizations. J. Nurs. Sch. 2018, 50, 558-566. [CrossRef] [PubMed]

43. Chênevert, D.; Jourdain, G.; Cole, N.; Banville, B. The role of organisational justice, burnout and commitment in the understanding of absenteeism in the Canadian healthcare sector. J. Health Organ. Manag. 2013, 27, 350-367. [CrossRef]

44. Rydstedt, L.W.; Lundh, M. Work demands are related to mental health problems for older engine room officers. Int. Marit. Health 2012, 63, 176-180.

(C) 2020 by the authors. Licensee MDPI, Basel, Switzerland. This article is an open access article distributed under the terms and conditions of the Creative Commons Attribution (CC BY) license (http://creativecommons.org/licenses/by/4.0/). 